\title{
Development and Construction of LED Lamp Power Supply Cover Based on the Design Concept for Injection Molding
}

\author{
Patryk BORKOWSKI ${ }^{1}$ and Krzysztof TWARDOCH ${ }^{2}$ \\ Warsaw University of Technology
}

\begin{abstract}
This paper presents multistage process and complexity involved in construction design from initial planning to final CAD models. The purpose of the presented project was to design a cover for the power supply for the LED lamp manufactured by the company based on various design concepts. The work involved in this project was divided into 2 stages. Stage 1 involved construction of the cover using one variant of the design concept. Stage 2 presented a second variant of the design concept. Many design modifications resulted in variety of models adhering to technological objectives and external aesthetics (verified by designer). This paper underlines the extent and complexity of construction design with multiple adjunctive and interrelated stages, where the use of technological innovations in engineering can speed up construction.
\end{abstract}

Keywords. injection molding, guidelines to plastic product design, construction process, industrial desing project, CAD design, FEA simulation, FEM

\section{Introduction}

The paper presents complex and multistage process of construction of an everyday use object (as identified in the title) from initial design to final CAD models. The stages of creating a new product covered various aspects of technology and design concept, and the most appropriate variant of the concept is repeatedly a key factor in accepting the proposed solutions. The paper describes interwoven relationship of two fields: engineering and industrial design by widely established co-operation between constructor-designer roles. The important factors applied in this project were technological concepts of high pressure forming (injection molding). Its development is the fastest growing branch of processing elements from thermoplastics [4]. It allows to create any shape in a relatively short time. The greatest advantage of this technology is the ability to produce a completed product directly after taking it out of mold [5]. However, the key aspect of effective injection molding is the process of building of a manufactured part. It is important for the designer to understand the molding process, its capabilities and its limitations. Factors such as wall thickness, draft to parting plane and radius of sharp corners determine the success of this production technology. Multiple publications and industry guidelines are available to explore technology of plastic part design $[6,7,8,9,10]$.

\footnotetext{
${ }^{1}$ Corresponding Author, Mail: patryk.borkowski97.pb@gmail.com.

${ }^{2}$ Corresponding Author, Mail: krzysztof.twardoch@pw.edu.pl.
} 


\section{Methods}

The project involved multistage (iterative) process shown in Figure 1. Like in every research, verification of the process is vital. This project used a discussion panel where different conceptual variation between construction group and industrial designer were debated. Ideas, comments and observations regarding design concepts and construction variants were exchanged. Frequently, during the discussions new ideas about shape or production process were identified (illustrated further in the article). The variability of opinions reflected the mix of professionals included in the manufacturing process (from mechanical to artistic approach). To achieve the final products several dozens steps were undertaken. They included tools such as 3D CAD design, numeric simulation FEA and visualisation tools to present realistic image of CAD models.

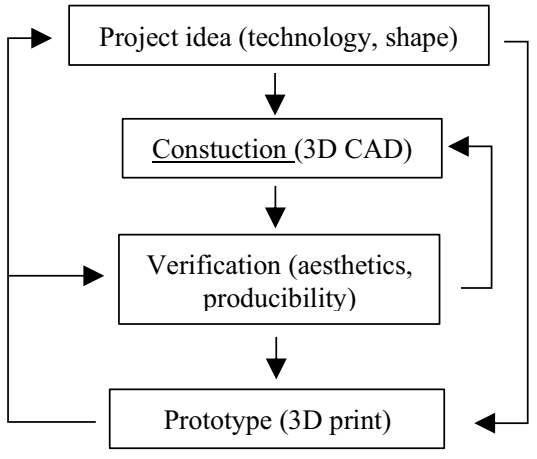

Figure 1. Multistage process of the project.

\section{Aim}

The aim of the project (which is presented in this paper) was to create the construction process of power supply cover for LED lamp, model Tablet produced by company NC.ART (Figure 2), using the design concept. The cover was to meet all the design and construction criteria identified by the NC.ART, including the production technology (plastic injection).

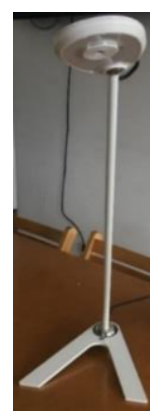

Figure 2. Image of NC.ART LED lamp, model Tablet.

\section{Origin of the project}

Issues discussed in this article are the results of working relationship between the Warsaw University of Technology and NC.ART company [1]. The initiative was to create own cover for the power plug for existing LED lamp (Figure 2) by the NC.ART company. At the start the NC.ART company presented their progress to date including hand-made power supply cover prototypes (Figure 3). However, after

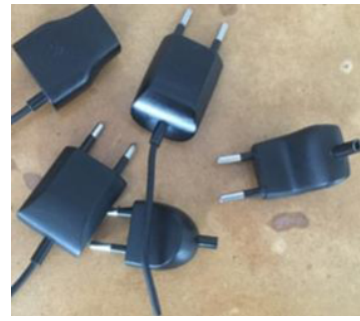

Figure 3. Hand-made prototypes of power supply cover.

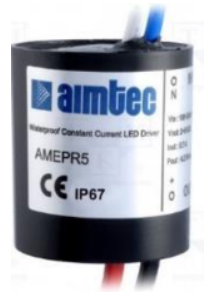

Figure 4. Driver AIMTEC AMEPR5, drive assembly (Chinese production) the light was flickering which was unacceptable for the final product. Therefore, the company directors decided to create customised cover for the AIMTEC AD/DC LED driver as the universal ones did not meet the shape criteria. At this point the authors of this article were approached. 


\section{Power supply construction criteria}

During initial talks NC.ART company identified their construction criteria. Technological aspects of the cover construction were as follows:

- $\quad$ division of the cover into parts and to identify parting line of mold (with recommended use of two-plate mold),

- method of connecting the part of power supply cover,

- define internal electrical connections,

- method of preventing the cable from being pulled out,

- ribs strengthening the construction,

- localising the components: an electric plug (Figure 5), the driver AIMTEC (Figure 4), a cable strain relief (Figure 6).

Construction criteria of the external shape of the cover

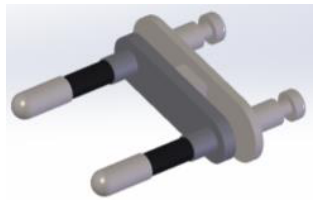

Figure 5. Electrical plug.

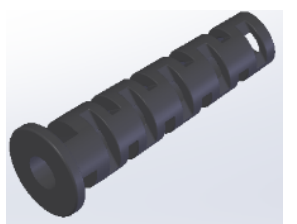

Figure 6. Cable strain relief. were based on two design concepts - concept I (Figure 7) and concept II (Figure 8). They were created in the CAD geometrical model, which was developed by the design on the basis of internal parts dimensions (for example: electrical plug - Figure 5).

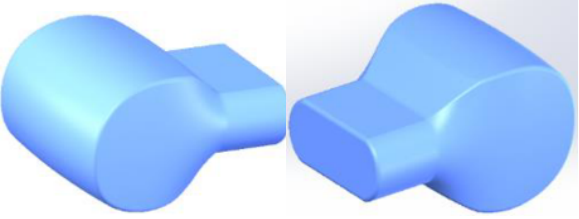

Figure 7. CAD geometrical model concept I.

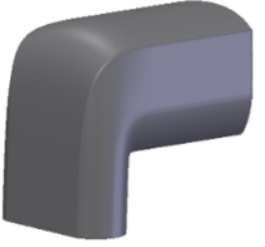

Figure 8. CAD geometrical model concept II.

\section{Implementation}

The construction of the project was carried out by the two mechanical engineers whereas NC.ART designer was responsible for the design concept. Regular meetings between the group and the designer, where the CAD models were discussed, ensured quality and sustainability of the work.

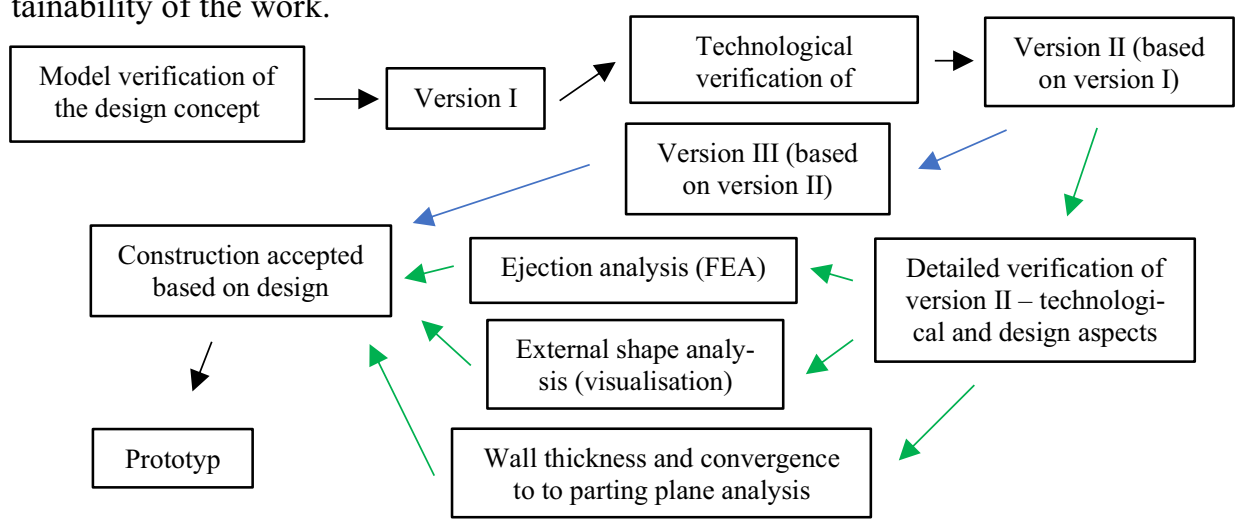

Figure 9. Design concept I step by step creation. 


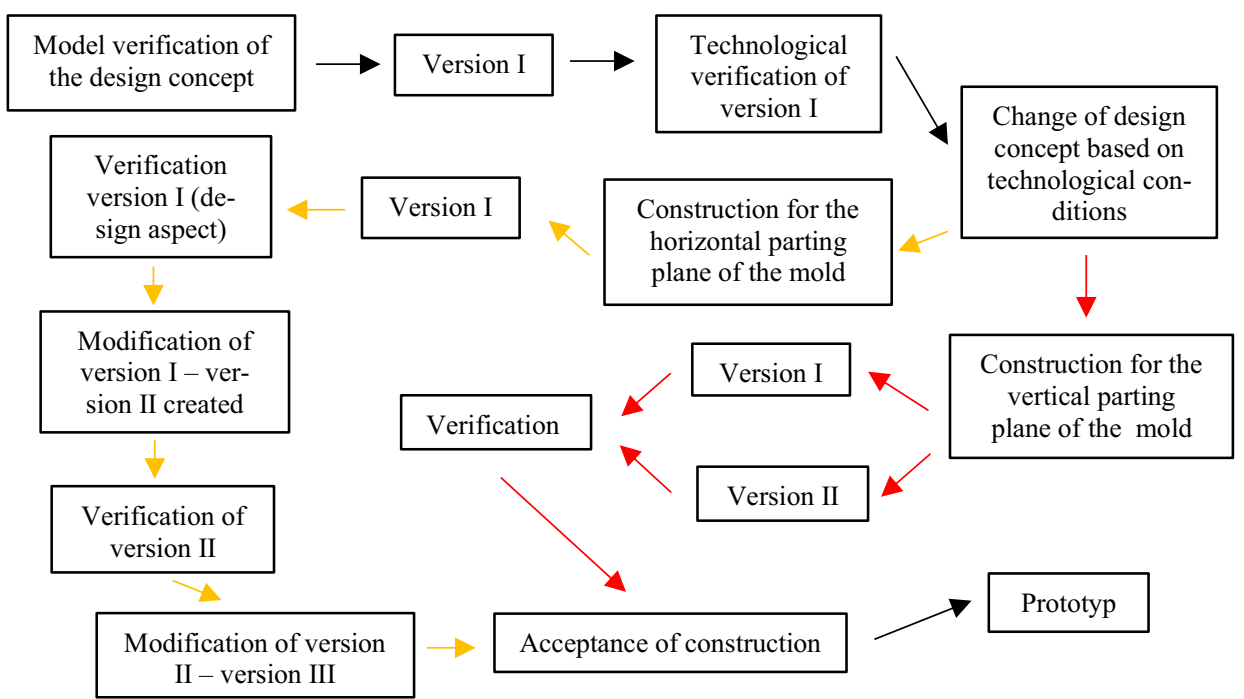

Figure 10. Design concept II step by step creation.

Variety of solutions for both concepts were created simultaneously. Nevertheless, to present systematic construction process of each they are described separately. This way it is possible to explain the multistage design process and the workload of creating the construction from the design concept. Figure 9 and Figure 10 illustrate the steps taken according to each concept, whereas more detail description of their key elements are presented further in the article.

\subsection{Concept I}

Initial project, the $\mathrm{CAD}$ model of design concept $\mathrm{I}$, was verified by the designer through measuring all sketches and operations utilised during the build. This enabled the use of SolidWorks parametrics during further construction. In version I of concept I wall thickness was identified based on overall dimensions of the model. Then parting plane of the form was chosen and all construction elements specified in the initial criteria were created. Figure 11 presents the version I of the cover.
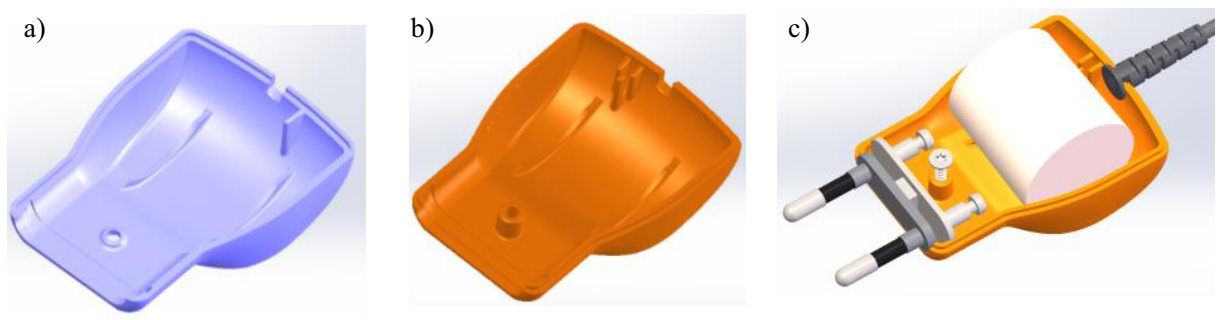

Figure 11. Cover version I of concept I. a) lower part, b) upper part, c) internal elements of the cover.

The next step was to verify the power supply cover using technological testing including wall draft to parting plane of the form as shown in Figure 12. It became apparent that the construction did not meet the minimal draft angle (equal to $1^{\circ}$ ) which is vital to successful ejection of a part from the mold. Too many construction errors would not deem the 
form suitable for designer review, therefore, modification of version I was undertaken. Technologically corrected version II is presented in Figure 13.

a)

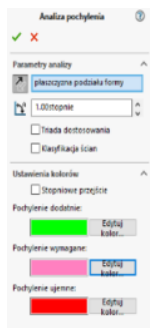

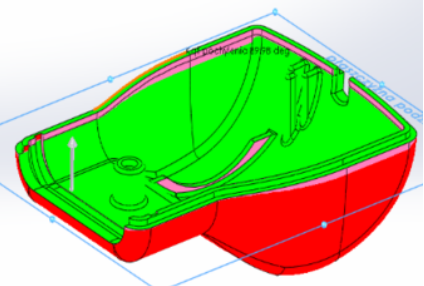

b)

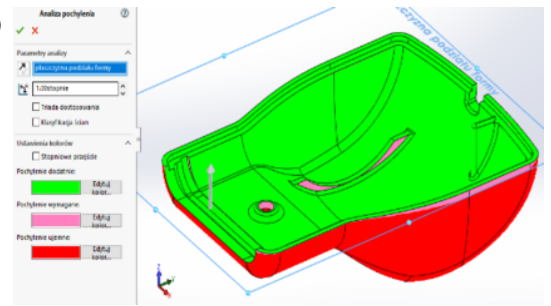

Figure 12. Analysis of draft to parting plane of the form version I a) part A and b) part B. The areas of a draft angle of $0-1^{\circ}$ are marked in pink; all other areas of a greater draft angle are marked in green and red.

a)

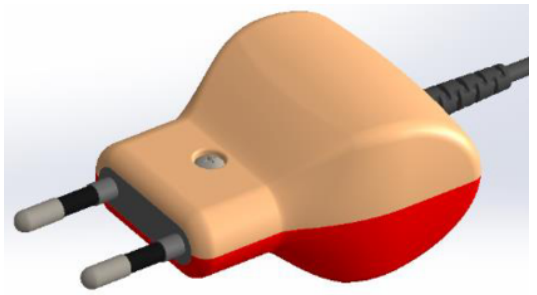

b)

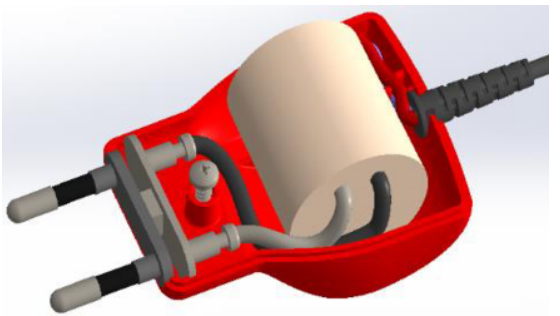

Figure 13. A) Concept I version II, B) A view of all power supply cover including all internal parts.

During construction of version II internal placement of electrical cords was taken into consideration. This identified that the internal space of the cover will have to be increased, as the clearance between internal elements was too small. Finally, the model met all construction criteria and further detailed technological testing of concept I version II was undertaken. The analysis included:

- injection of plastic into form volume analysis using FEM,

- walls draft to parting plane keeping minimal angle,

- $\quad$ wall thickness in plastic part,

- model visualisation with actual facture, colours and light reflection.

Injection analysis also contained the evaluation of size of thermal deformations (warpage) after ejecting parts from the mold, Figure 14 incorporating finite elements method. Mesh surface was used in view of thin-walled model and degree of precision in calculations.

Further analysis concentrated on analogical verification of model's wall draft to parting plane of two-plate mold as shown in Figure 12. Additionally, wall thickness verification identified lack of any abnormalities with uncontrolled localised thickness changes.

At the end of verification of version II visual effect and quality of surfaces by reflections was evaluated. After technological testing mechanical engineers used photorealistic visualisation system to present the final result of version II to NC.ART designer (Figure 15). 
a)
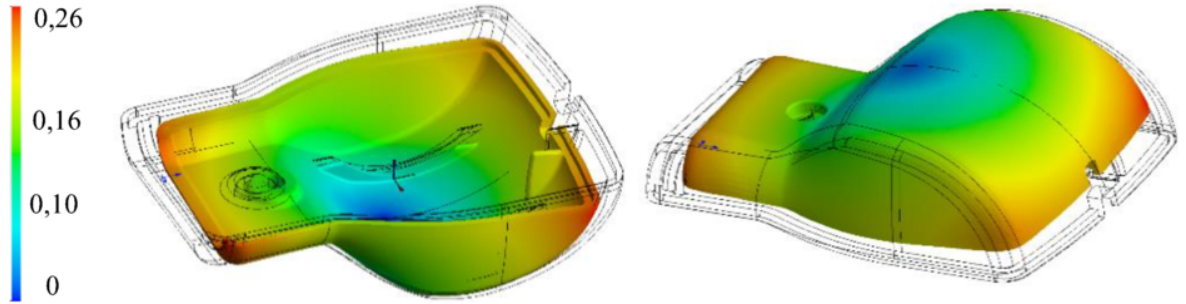

b)
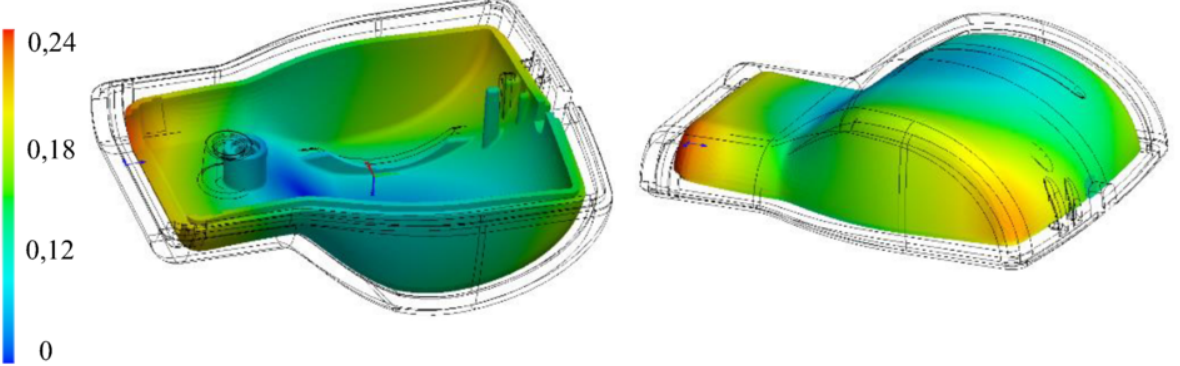

Figure 14. Accidental distribution of deformations (in $\mathrm{X}, \mathrm{Y}$, and $\mathrm{Z}$ axis) of part a) A and b) B of the form in [mm], scale $20 x$ greater after cooling down to $30^{\circ} \mathrm{C}$. Sketch in black represent the model after taking it out of the form, colours though present it after thermal cooling.
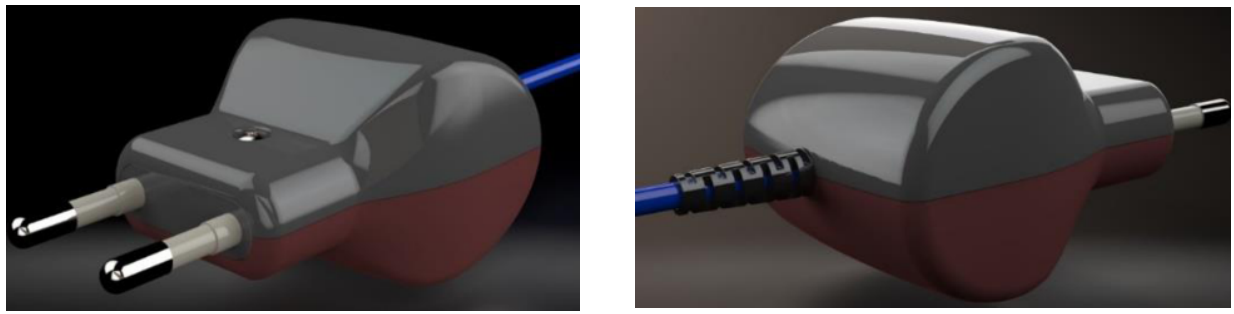

Figure 15. Realistic visualisation of version II model.

The model was positively received, with minor suggestion of moving the screw placement to the back. It was taking into consideration possible thermal displacement during injection molding process (Figure 14.). Additionally, the change would not only add to visual value of the model (Figure 16), but also improve functionality of a cable stoppage. Considering vast and long experience in the industry designer's suggestion was implemented and version III of concept I was constructed (Figure 17).

Figure 16. Screw placement change (draft by T. Rudkiewicz, NC.ART).
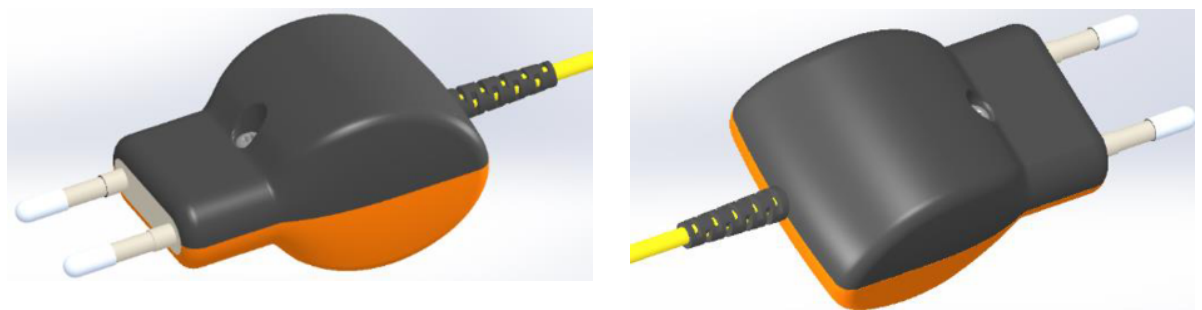

Figure 17. Version III based on version II. 
As the results of the work on concept I were satisfactory for both sides its construction was finilised on version III. NC.ART would produce prototype of version III using rapid prototyping (FDM) method based on which further improvement would have been made.

\subsection{Concept II}

Work on concept II (Figure 8) started by verification of the initial model. Version I was then created incorporating all elements according to the technological criteria. Figure 18 illustrates the proposed cover. The results was presented to the NC.ART designer. Dur-
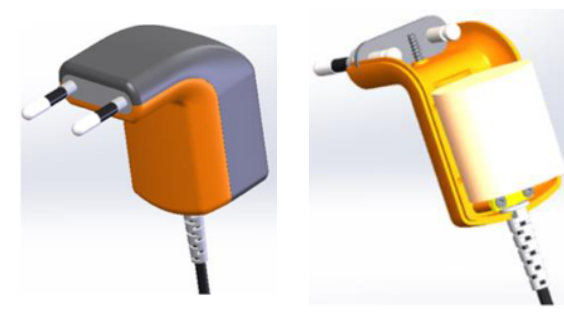

Figure 18. The power supply cover version I of concept II including internal elements. ing the verification process it was decided that proposed parting plane was too complicated. Despite adhering to the shape suggested in the design concept, the construction cost of this form would have been to high. Arbitrarily, the decision was made to change the division of the mold as seen in Figure 19. However, it became apparent that there was a problem with convergence when adjusting version I to the new parting plane (Figure 20). Therefore, due to technological and economic factors it was not possible to create the shape according to initial design concept (Figure 8). Unfortunately, the designer did not present detailed criteria for external shape. Hence, the mechanical engineers had to propose alternative cover shapes of version I horizontal and vertical parting planes. The results of construction in horizontal and vertical parting forms are described separately below.

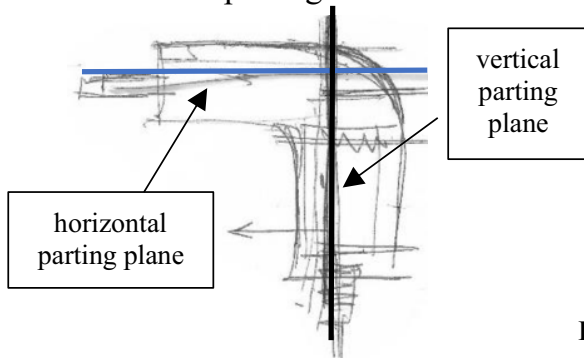

Figure 19. Proposed parting form of concept II (draft by T. Rudkiewicz. NC.ART).

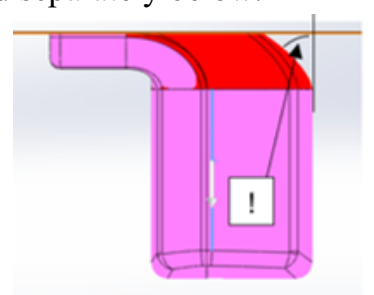

Figure 20. Problem with the version I new form parting planes (Figure 23) convergence.

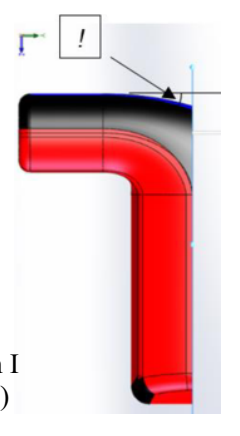

\subsubsection{Horizontal parting plane}

In the first version of this variant construction elements, such as: strengthening ribs, lip and groove to assembly both parts of the cover, boss and hole for screw were created. More detailed technological aspects were also taken into consideration, but these are not included in the article. The external shape of version I (Figure 21) in this plane was presented to the designer. Unfortunately, the

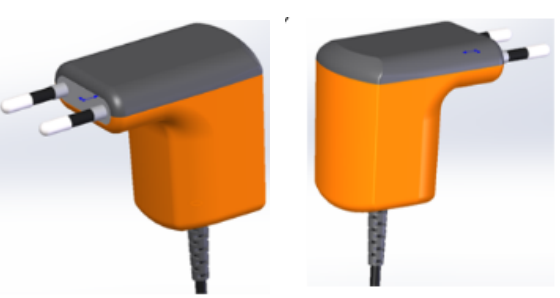

Figure 21. Version I for horizontal parting plane of the form. 
back part did not meet their expectations and illustrative sketch of the cover was presented by the designer, see Figure 22 . On its basis small adjustment was made in the CAD model to create plane that would crop the back part of the cover. It enabled any shape change to this part. Version II was created on the basis of above mentioned corrections (Figure 23).

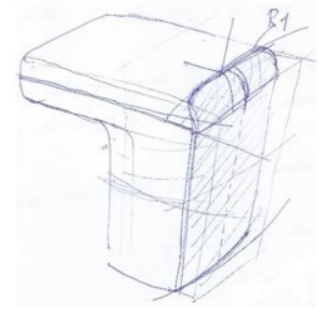

Figure 22. Version II draft drawing (auth. T. Rudkiewicz, NC.ART).
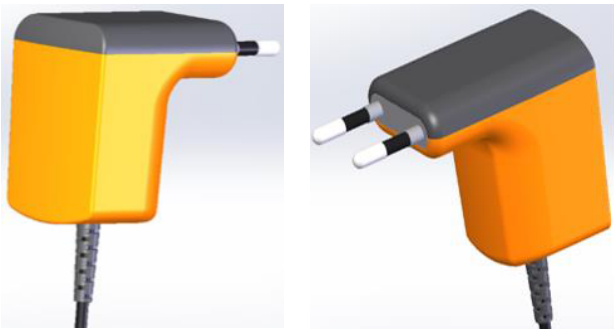

Figure 23. Power supply cover version II.

The designer accepted the shape of version II (Figure 23). At this stage it was proposed to create the shaped element - a snap-fit - to connect two parts of the version II cover (Figure 24). Considering endurance issues and guidelines presented by Bayer Material Science [12] analytical calculations were taken to choose the snap-fit dimensions. Version III as a modification of version II is presented in Figure 25.

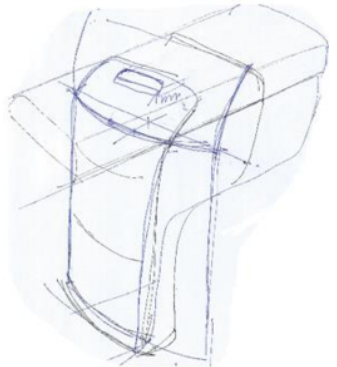

Figure 24. Snap-fit draft drawing (auth. T. Rudkiewicz, NC.ART).
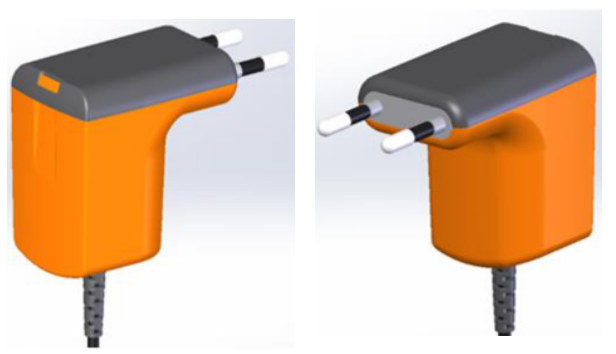

Figure 25. Version III for horizontal parting plane of the form.

At this stage both models of version II and III were accepted by the designer and met all technological criteria. The company management found the use of snap-fit in version III very interesting, which was not at all considered at the start of the project.

\subsubsection{Vertical parting plane}

First proposed version for vertical parting plane of concept II is presented in Figure 26. For this solution it was decided to use snap-fit in the back part of the cover, which would strengthen the blocking elements to prevent cable being pulled out. During verification meeting proposed cover (Figure 26) met designer's expectations,
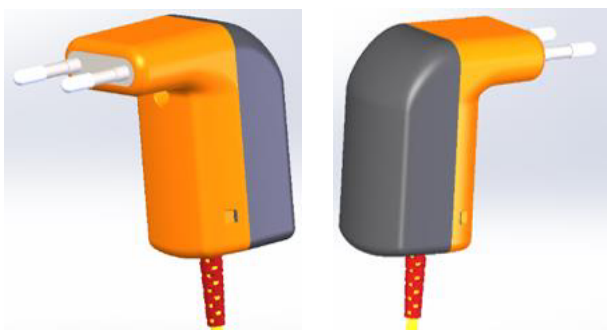

Figure 26. Version I of vertical parting plane of the form (Figure 23).

despite lack of hints of its external shape. Additionally, one of the mechanical engineers 
suggested to change the screw for a few bigger snap-fits to connect two parts of the cover. It was thought that the cost of construction will be reduced as smaller amount of plastic would be used during production. However, the snap-fit solution would significantly modify the external shape of version I (Figure 26) to ensure visually attractive integration of the snap-fit into the cover. Figure 27 presents initial sketch of this solution. All requirements of this solution created exceptional construction challenge, the effect of which is presented in Figure 28. As the NC.ART designer accepted version II for vertical parting plane of the mold the construction work was completed at this stage.

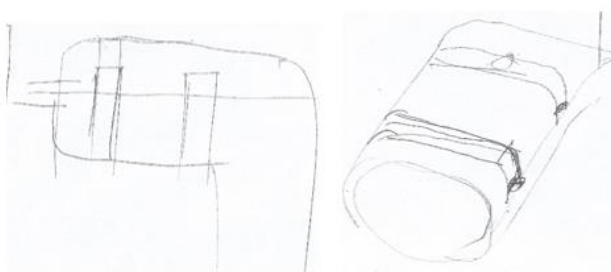

Figure 27. Draft drawing of snap-fit in version II (auth. T. Rudkiewicz, NC.ART)

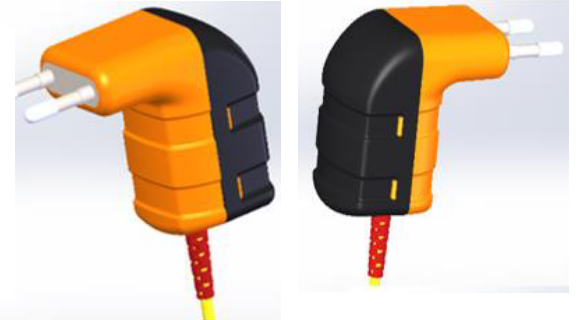

Figure 28. Version II of vertical parting plane of the form.

\section{Conclusions}

Development and construction of a new product (a small size power supply cover for LED lamp) involves many iterations during design process and depends on collaboration of many people from different industries. It is more pronounced when mutual interests (designer - constructor), openness for new ideas and changes, thinking outside of the box and exploring new routes of development (not sticking to established paths) are present. This project required co-operation and understanding between two different approaches to construction (creating) issues: engineering and design. As presented in the article several wrong suggestions or even mistakes are inevitable parts of such project. However, those mistakes and knowledge and experience of each team member contributed to a consensus and resulted in creation of interesting useable forms for the power supply cover. The aim of this project was to illustrate the complexity and diversity of developing construction even of a seemingly simple object, such as a power supply cover. It is especially noticeable when the best construction and technological aspects are to be met according to the company's design requirements. The closing opinion is worth mentioning that the continuous development of the new model is still ongoing; it is a long and tedious process.

\section{Acknowledgement}

The authors would like to thank Monika Krupa for assistance with translation. 


\section{References}

[1] NC.ART, 2012, https://www.wzornictwo-przemyslowe.pl, Accessed: DATA 14.02.2020. [Online]

[2] J. Hasenauer, D. Küper, E. Jost, I. Welsh, L. Welsh, 201410 Gtównych Zasad Stosowanych $w$ Konstrukcji Detali z Tworzyw Sztucznych, Tworzywa.Pl, Accessed: 30.06.2019. [Online]. Available: http://www2.dupont.com.

[3] H. Zawistowski, D. Frenklem, Konstrukcja form wtryskowych do tworzyw termoplastycznych, WNT, Warsaw, 1984.

[4] Wroclaw University of Science and Technology, Budowa wtryskarek, Accessed: 21.06.2019. [Online]. Available: http://www.tworzywa.pwr.wroc.pl.

[5] W. Traczyk, 2018, Formowanie wtryskowe tworzyw sztucznych, Accessed 09.02.2020. [Online]. Available: https://www.magazynprzemyslowy.pl/produkcja/Formowanie-wtryskowe-tworzywsztucznych,11142,1.

[6] A. Smorawiński, Wtrysk elastomerów, PLASTECH, Warsaw, 2001

[7] C. Maier, Design Guides for Plastics, Tangram Technology Ltd., 2009.

[8] The Bayer Corporation, Part and Mold Design, Engineering Polymers, Bayer Material Science, 2000.

[9] J. Mydlikowski, 2015, Dobre praktyki w konstruowaniu elementów z tworzyw, Accessed: 10.09.2019. [Online]. Available: https://projektowanieproduktow.wordpress.com.

[10] Plastech, 2002, Tworzywa termoplastyczne, Accessed: 22.06.2019. [Online]. Available: https://www.plastech.pl.

[11] Aimtec, AMEPR5-AZ, AC/DC LED Driver Series, Accessed: 21.06.2019. [Online]. Available: http://www.aimtec.com.

[12] Bayer Material Science, Snap-fit for Plastics: a Design Guide, Pittsburgh, 2002 